\title{
The Thyroid Stimulating Hormone and Free Thyroxine Levels in Correlation with Serum Bilirubin in Neonatal Jaundice
}

\author{
Elvira Dwijayanti, MI. Diah Pramudianti, Dian Ariningrum \\ Department of Clinical Pathology, Faculty of Medicine, Sebelas Maret University/Dr. Moewardi Hospital, Surakarta, Indonesia. E-mail: \\ el_pee_raa@yahoo.com
}

\begin{abstract}
Congenital hypothyroidism is known to cause prolonged hyperbilirubinemia in neonates. It also correlates with delayed maturation of the activity of the uridine diphosphate glucoronosyltransferase (UDPG-T) enzyme. Thus, this study was performed to analyze the correlation of TSH and FT4 levels with serum bilirubin in neonatal jaundice. This observational analytical study with a cross-sectional approach was conducted on 64 neonatal patients with jaundice in Dr. Moewardi General Hospital, Surakarta during September-November 2019. The data comparison and correlation were analyzed with Mann-Whitney and the Spearman test. A p-value of $<0.05$ was considered significant with $95 \%$ Confidence Interval (CI). The study variables comprised of total bilirubin of $12.7(6.28-23.5) \mathrm{mg} / \mathrm{dL}$, direct bilirubin of $0.8(0.30-6.61) \mathrm{mg} / \mathrm{dL}$, indirect bilirubin of $11.87(3.16-22.94) \mathrm{mg} / \mathrm{dL}$, TSH of $4.4(0.40-23.06) \mathrm{UIU} / \mathrm{L}$, and FT4 of $22.85 \pm 7.4 \mathrm{pmol} / \mathrm{L}$. The TSH and FT4 were moderately correlated with total bilirubin $r=-0.444 ; p=0.001$ and $r=-0.467 ; p=0.001)$, with indirect bilirubin $(r=-0.3362$; $p=0.03$ and $r=-0.411 ; p=0.001)$ and with direct bilirubin $(r=-0.257 ; p=0.040$ and $r=0.232 ; p=0.065)$, respectively. A moderate correlation of TSH and FT4 with total and indirect bilirubin, as well as a weak correlation between TSH and direct bilirubin were found, while no correlation was found between FT4 and with direct bilirubin. Thyroid function screening is recommended in neonates with jaundice, due to the importance of thyroid hormones in the function and formation of organs.
\end{abstract}

Keywords: Congenital hypothyroidism, neonatal jaundice, bilirubin, TSH, FT4

\section{INTRODUCTION}

Congenital hypothyroidism is a condition of the decreased thyroid gland or its malfunction since birth or decreased or malfunctioning of the thyroid gland acquired since a newborn due to anatomic abnormalities, metabolic disorders of thyroid hormone formation, or iodine deficiency. ${ }^{1}$

Congenital hypothyroidism is the most common cause of endocrine disorder in childhood and mental retardation, which can be prevented. ${ }^{2}$

The incidence of congenital hypothyroidism is 1:3000-4000 live births worldwide and 1: 3528 in Indonesia. ${ }^{3}$ Based on the Indonesian Pediatrician Association (IDAI) data in 2012, there were 906 children with congenital hypothyroid. Based on data from the Endocrinology Outpatient Clinic of Dr. Moewardi Hospital during 2011-2012, 33\% of the total annual patient visits were either newly or late-diagnosed congenital hypothyroidism. ${ }^{4}$

Routine examination to establish the diagnosis of congenital hypothyroidism is serum Free Thyroxine (FT4) or total thyroxine and Thyroid Stimulating Hormone (TSH). Low FT4 and increased TSH levels confirm the diagnosis of primary congenital hypothyroidism, whereas low FT4 with low TSH levels lead to the diagnosis of secondary congenital hypothyroidism. ${ }^{5}$

Congenital hypothyroidism is known as one of the causes of prolonged hyperbilirubinemia and it is correlated with delayed maturation of the activity of Uridine Diphosphate Glucoronosyl Transferase (UDPG-T) enzyme. UDPG-T activity increases steadily to reach adult levels at 14 weeks of birth. ${ }^{6}$ Thyroid hormone stimulates the activity of heme oxygenase-1 (HO-1), which is the main enzyme responsible for bilirubin production. The thyroid hormone decreases the enzymatic activity of UDPG-T, which stimulates the conjugation of bilirubin, facilitating the excretion of bilirubin. ${ }^{7}$

Neonatal jaundice is an excessive accumulation of bilirubin in the blood characterized by jaundice on the skin, sclera, mucosa, and urine, it is observable when the serum bilirubin level exceeds $5 \mathrm{mg} / \mathrm{dL}$. Jaundice caused by a normal process occurs in $25 \%-0 \%$ of all healthy full-term neonates. ${ }^{8}$

Prolonged jaundice is found in approximately $10 \%$ of neonates with hypothyroidism. 
Hypothyroidism has been reported in several studies as the etiology of jaundice, which appears in the first week of life.

Therefore, this study aimed to analyze the correlation between TSH and FT4 levels with serum bilirubin in neonatal jaundice.

\section{METHODS}

This observational analytical study with a cross-sectional approach was performed in the Clinical Pathology Installation of Dr. Moewardi Hospital Surakarta, from September 2019 until November 2019. The inclusion criteria were all newborns aged 2 to 7 days with neonatal jaundice selected by consecutive sampling whose parents agree to participate in research by signing informed consent. In addition, exclusion criteria were newborns with $A B O$ incompatibility, biliary congenital abnormalities, severe infections, and CRP levels $>6 \mathrm{mg} / \mathrm{dL}$. The data were taken from medical records of patients. Based on gestational age, all subjects were divided into two groups such as preterm and a term. Preterm was defined as babies born alive before 37 weeks of pregnancy, while the term was babies born alive from 37-42 weeks of pregnancy. Total $3 \mathrm{~mL}$ venous blood was taken without anticoagulants as the sample for the measurement of TSH and FT4 levels. The samples were centrifuged to separate serum and were then collected in aliquots. Serum was used for measurement of TSH, FT4, total bilirubin, and direct bilirubin. TSH and FT4 levels were measured by the ECLIA method using the Cobas E411 instruments; while total bilirubin and direct bilirubin levels were measured by the vanadate oxidation method using the ADVIA 1800 chemical analyzer. Sampling and tests were carried out at the same time. A performance test was carried out before the test of the research sample. The $p$-value stands for probability and measures how likely it is that any observed difference between groups is due to chance, a p-value of $<0.05$ was considered significant with 95\% Confidence Interval (CI), and accuracy tests were included in the analytical test.

Descriptive analysis was performed to describe the variable characteristics of subjects. Variables with nominal scales were presented as frequencies and percentages. The data normalization test was preceding performed followed by the Pearson correlation test for normally distributed data and the Spearman correlation test for abnormally distributed data. Data were processed using a statistical computer program. A p-value $<0.05$ was considered significant with a $\mathrm{CI}$ of $95 \%$.
This study was approved by the Biomedical Research Ethics Committee of Dr. Moewardi Hospital in Surakarta with the number 1.088/IX/HREC/2019 and the parents or guardians of prospective subjects by signing informed consent.

\section{RESULTS AND DISCUSSIONS}

This study was performed in 64 neonatal jaundice in-patients in the neonatal High Care Unit (HCU) of Dr. Moewardi Hospital in Surakarta and laboratory tests were performed in the Clinical Pathology Installation Dr. Moewardi Hospital in Surakarta.

The baseline characteristics of subjects in this study (Table 1) were grouped into three groups based on gestational age, i.e. preterm and at term as well as total. The comparison between two groups of subjects based on gestational age was analyzed with the Mann-Whitney test since the data were not normally distributed. Significant differences in birth weight, body length, mode of delivery, and duration of jaundice were found between both preterm and term groups in term with $p<0.05$, despite no significant difference was found in other variables.

Based on the results of measurements of TSH and FT4 levels in this study, 45 (70.3\%) subjects were classified in euthyroid status with TSH levels $<9$ $\mathrm{uIU} / \mathrm{mL}$ and normal FT4 (11.6-29.6 pmol/L). A number of 7 (10.9\%) subjects with disorders of thyroid function were classified in the subclinical hypothyroid category, while TSH levels $>9 \mathrm{uIU} / \mathrm{mL}$, and FT4 levels were still normal (11.6-29.6 pmol/L). A total of $7(10.9 \%)$ subjects were classified in subclinical hyperthyroidism with TSH levels 9-25 $\mathrm{uIU} / \mathrm{mL}$ and FT4 levels $>29.6 \mathrm{pmol} / \mathrm{L}$, while the rest 5 $(7.8 \%)$ subjects were classified in secondary hyperthyroidism with TSH levels > 9uIU/mL and FT4 level $>29.6 \mathrm{pmol} / \mathrm{L}$

The data in this study were displayed in mean and standard deviation, as seen in Table 2.

A comparison of the average levels of TSH, FT4, total bilirubin, direct bilirubin, and indirect bilirubin based on the gestational age of $<37$ weeks (preterm) and $\geq 37$ weeks (term) was presented in the box plot (Figure 1).

Most of the data were not normally distributed; thus, the Spearman rank test was used for the bivariate analysis of TSH and FT4 correlations with bilirubin.

Most study subjects were classified in the euthyroid category, and hyperthyroid neonates were predominantly found compared to those with hypothyroidism. Neonatal hyperthyroidism is commonly caused by the passage of maternal thyroid receptor antibodies. This relatively rare 
condition has various manifestations including cholestasis, prematurity, and cardiomegaly. Often, signs of fetal hyperthyroidism, which can be observed in the third trimester are tachycardia, heart failure, preterm labor, and delayed intrauterine growth. Neonatal hyperthyroidism can also be observed at birth. Remission usually occurs between 20 to 48 weeks of life. Graves' disease is the most common manifestation of hyperthyroidism in neonates, especially in neonates born from mothers with autoimmune hypothyroidism that induces transplacental TSH antibodies. ${ }^{8}$

Table 1. The baseline characteristics of subjects based on gestational age

\begin{tabular}{|c|c|c|c|c|}
\hline Variąble & Total $(n=64)$ & Term $(n=39)$ & Preterm $(n=25)$ & $\mathbf{p}$ \\
\hline \multicolumn{5}{|l|}{ Gender } \\
\hline Male & 41 (64.1\%) & $26(66.7 \%)$ & $15(60 \%)$ & 0.591 \\
\hline Female & 23 (35.9\%) & $13(33.3 \%)$ & $10(40 \%)$ & \\
\hline Ages (day) ${ }^{a}$ & $5(2-7)$ & $4(2-7)$ & $5(2-7)$ & 0.333 \\
\hline 2-4 day & $30(46.8 \%)$ & $21(53.8 \%)$ & $9(36 \%)$ & \\
\hline 5-7 day & $34(53.2 \%)$ & $18(6.2 \%)$ & $16(64 \%)$ & \\
\hline Birth weight (gram) & $2725(900-3900)^{b}$ & $2967 \pm 410.2^{c}$ & $1966 \pm 613.4^{c}$ & $0.001^{*}$ \\
\hline Body length $(\mathrm{cm})$ & $47(31-52)^{c}$ & $48(42-52)^{c}$ & $43.8 \pm 3.8^{b}$ & $0.001^{*}$ \\
\hline Mode of delivery ${ }^{a}$ & & & & $0.002 *$ \\
\hline Spontaneous & $21(32.8 \%)$ & 7 (17.9\%) & $14(56 \%)$ & \\
\hline Sectio Cesarea & $43(67.2 \%)$ & $32(82.1 \%)$ & 11 (44\%) & \\
\hline Mother ages (years) ${ }^{b}$ & $31.11 \pm 6,2$ & $31.4 \pm 5.7$ & $30.6 \pm 7.1$ & 0.644 \\
\hline The duration of jaundice (days) ${ }^{c}$ & $5(2-28)$ & $5(2-16)$ & $9(2-28)$ & $0.025^{*}$ \\
\hline Breastmilk $^{a}$ & & & & 0.174 \\
\hline Yes & 47 (73.4\%) & 31 (79.5\%) & $16(64 \%)$ & \\
\hline No & $17(26.6 \%)$ & $8(20.5 \%)$ & $9(36 \%)$ & \\
\hline Gemelli $^{\text {a }}$ & & & & 0.646 \\
\hline No & 60 (93.8\%) & 37 (94.9\%) & 23 (92\%) & \\
\hline Yes & 4 (6.3\%) & 2 (5.1\%) & $2(8 \%)$ & \\
\hline $\operatorname{CRP}(\mathrm{mg} / \mathrm{dL})^{\mathrm{c}}$ & $0.155(0.01-4.4)$ & $0.15(0.01-4.4)$ & $0.19(0.01-3.3)$ & 0.825 \\
\hline Thyroid state & & & & 0.135 \\
\hline Euthyroid & 45 (70.3\%) & 25 (64.1\%) & 20 (80\%) & \\
\hline Subclinical hypothyroid & 7 (10.\%) & $4(10.3 \%)$ & $3(12 \%)$ & \\
\hline Subclinical Hyperthyroid & 7 (10.9\%) & $6(15.4 \%)$ & $1(4 \%)$ & \\
\hline Secondary Hyperthyroid & $5(7.8 \%)$ & 4 (10.3\%) & $1(4 \%)$ & \\
\hline
\end{tabular}

n: number, p: significance; cm: centimeter, preterm: < 37 weeks; term: $\geq 37$ weeks; CRP: c-reactive protein; mg/dL: milligrams per deciliter

a: Categorical data was displayed in numbers (percentages),

b: Normal data distribution (mean \pm standard deviation), Mann-Whitney was used for a comparison test

c: Abnormal data distribution [median (minimum-maximum)], independent T-test was used for a comparison test

${ }^{*} p<0.05$ : significant, confidence intervals of $95 \%$

Table 2. Comparison of research variables by gestational age

\begin{tabular}{|c|c|c|c|c|}
\hline Variable & Total & Term $(n=39)$ & Preterm $(n=25)$ & $\mathbf{p}$ \\
\hline Total bilirubin $(\mathrm{mg} / \mathrm{dL})^{\mathrm{a}}$ & $12.7(6.3-23.6)$ & $14.5 \pm 4.3$ & $12.3(6.9-23.6)$ & 0.265 \\
\hline Direct bilirubin $(\mathrm{mg} / \mathrm{dL})^{\mathrm{a}}$ & $0.8(0.3-6.6)$ & $0.9(0.4-6.4)$ & $0.7(0.3-6.6)$ & $0.048^{\prime}$ \\
\hline Indirect bilirubin $(\mathrm{mg} / \mathrm{dL})^{a}$ & $11.9(3.2-22.9)$ & $13.3 \pm 4.7$ & $11.45(6.4-22.9)$ & 0.305 \\
\hline $\mathrm{TSH}(\mathrm{UIU} / \mathrm{mL})^{\mathrm{a}}$ & $4.4(0.4-23.1)$ & $5.5 \pm 3.9$ & $4(0.6-23.1)$ & 0.531 \\
\hline FT4 $(\mathrm{pmol} / \mathrm{L})^{\mathrm{b}}$ & $22.9 \pm 7.4$ & $21.3 \pm 6.7$ & $23.9 \pm 7.8$ & 0.122 \\
\hline
\end{tabular}

Note: TSH: Thyroid Stimulating Hormone, FT4: Free Thyroxine, mg/dL: milligrams per deciliter, uIU/mL: international micro units per milliliter, pmol/L: picomol per liter.

${ }^{*} p<0.05$ : significant, confidence intervals of $95 \%$

a: Abnormal data distribution [median (min-max)], Mann-Whitney was used for a comparison test; b: Normal data distribution (mean $\pm \mathrm{SD}$ ), independent $T$-test was used for a comparison test. 
Subclinical hypothyroidism ( $\mathrm{SCH}$ ) is a condition when the serum TSH level exceeds the upper limit of the reference range, while serum free $\mathrm{T} 4 \mathrm{is}$ within its reference range. ${ }^{9}$

The common etiology of $\mathrm{SCH}$ in newborns is transient hyperthyrotropinemia in newborns, the

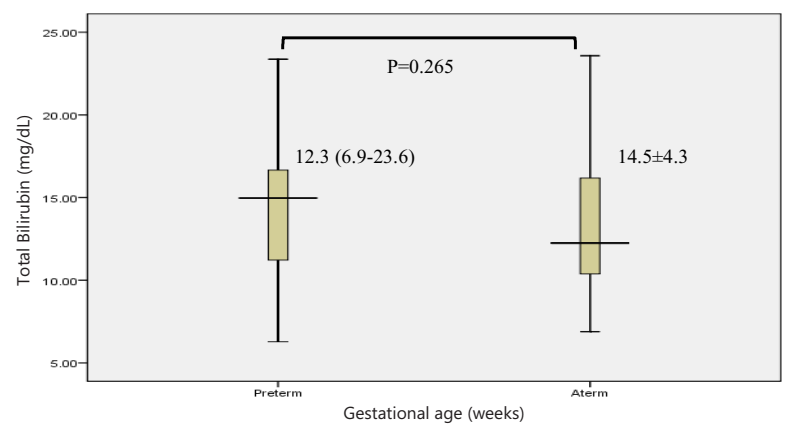

Total bilirubin boxplot based on gestational age

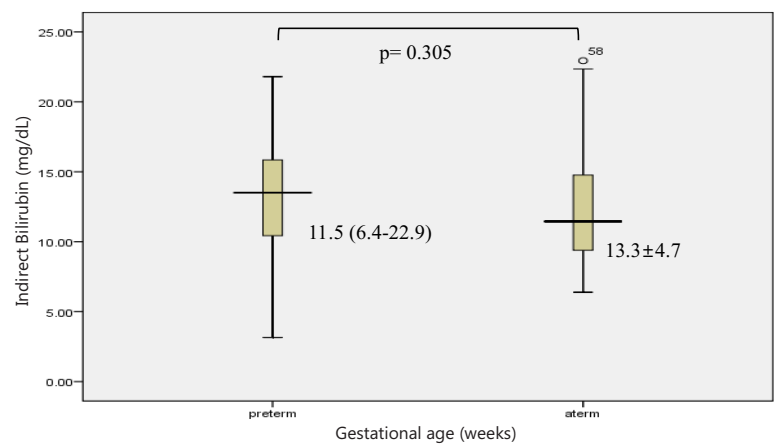

Indirect bilirubin boxplot based on gestational age disorder of thyroid hormone metabolism, maternal autoimmune thyroid diseases, exposure to iodine, genetic etiology of $\mathrm{SCH}$, TSH Resistance Syndrome (RTSH), loss-of-function mutations in TSH receptor, pseudohypoparathyroidism, thyroid dysgenesis. ${ }^{10}$

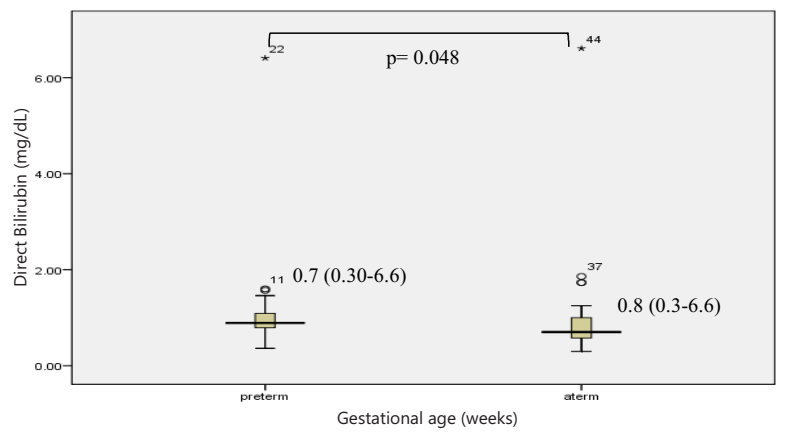

Direct bilirubin boxplot based on gestational age

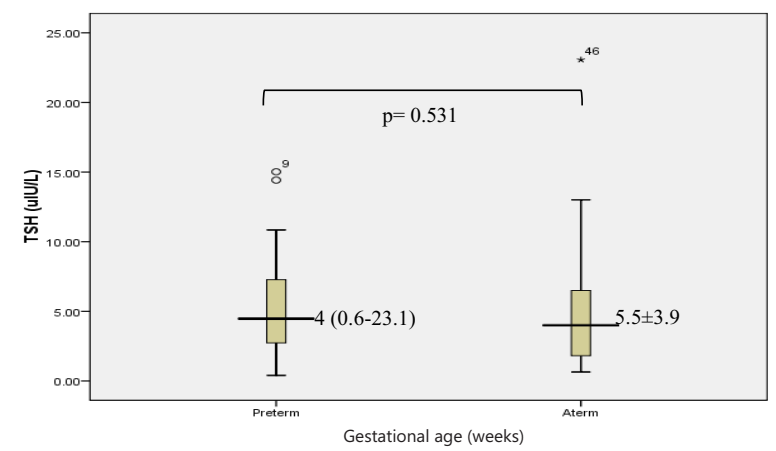

TSH boxplot based on gestational age

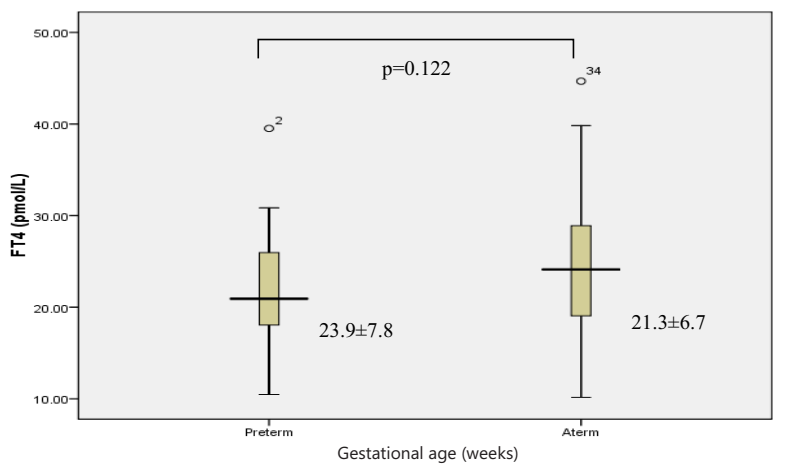

Ft4 boxplot based on gestational age

Figure 1. A comparison of average levels of TSH, FT4, total bilirubin, direct bilirubin, and indirect bilirubin based on gestational (Mann-Whitney test)

Table 3. The correlation between TSH, FT4, and serum bilirubin in all subject

\begin{tabular}{ccccccc}
\hline \multirow{2}{*}{ Variable } & \multicolumn{2}{c}{ Total Bilirubin } & \multicolumn{2}{c}{ Direct Bilirubin } & \multicolumn{2}{c}{ Indirect Bilirubin } \\
\cline { 2 - 7 } & $\mathrm{r}$ & $\mathrm{p}$ & $\mathrm{r}$ & $\mathrm{p}$ & $\mathrm{r}$ & $\mathrm{p}$ \\
\hline TSH & -0.44 & $0.001^{*}$ & -0.26 & $0.040^{*}$ & -0.36 & $0.003^{*}$ \\
FT4 & -0.47 & $0.001^{*}$ & -0.23 & 0.065 & -0.41 & $0.001^{*}$ \\
\hline
\end{tabular}

Note: Spearman rank test, TSH: Thyroid Stimulating Hormone; FT4: Free Thyroxine; r: correlation, $p<0.05$ : significant, confidence intervals of $95 \%$ 


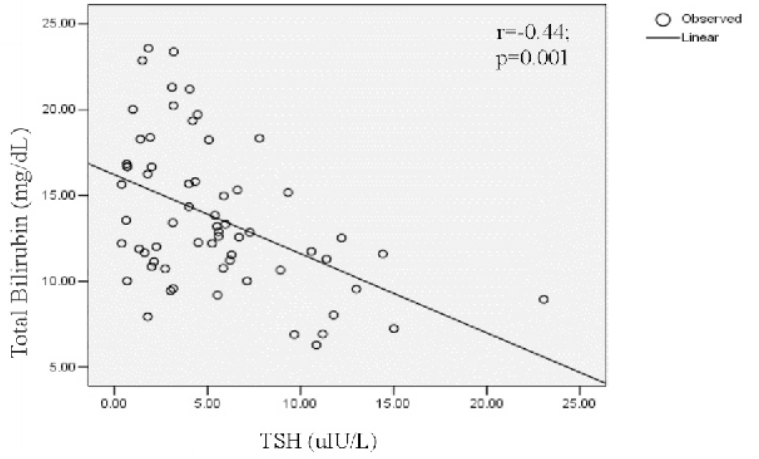

The scatter plot of correlation between TSH and total bilirubin

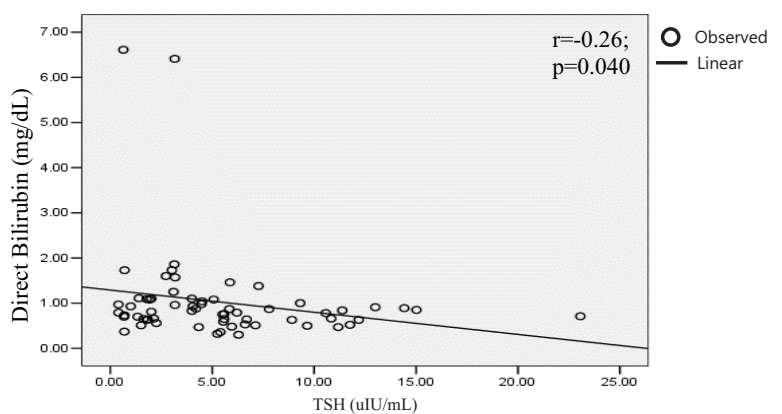

The scatter plot of correlation between TSH and direct bilirubin

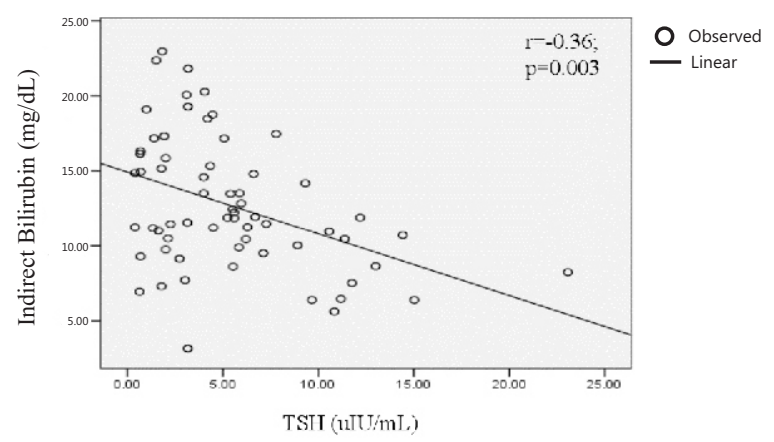

The scatter plot of correlation between TSH and indirect bilirubin

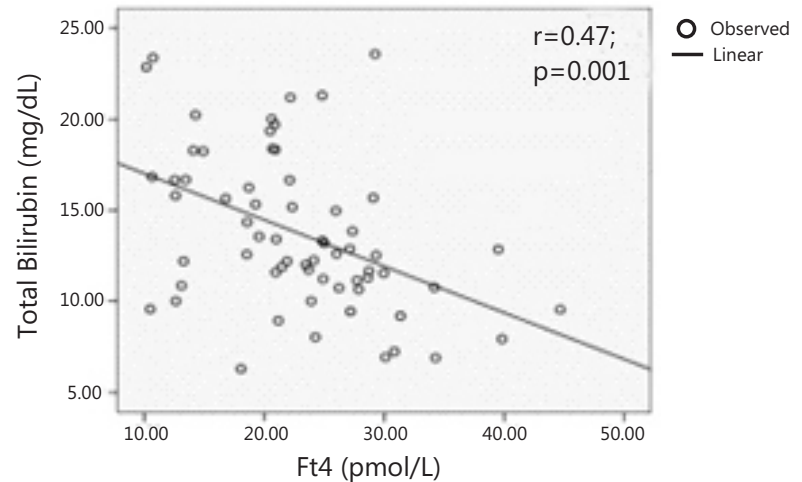

The scatter plot of correlation between FT4 and total bilirubin

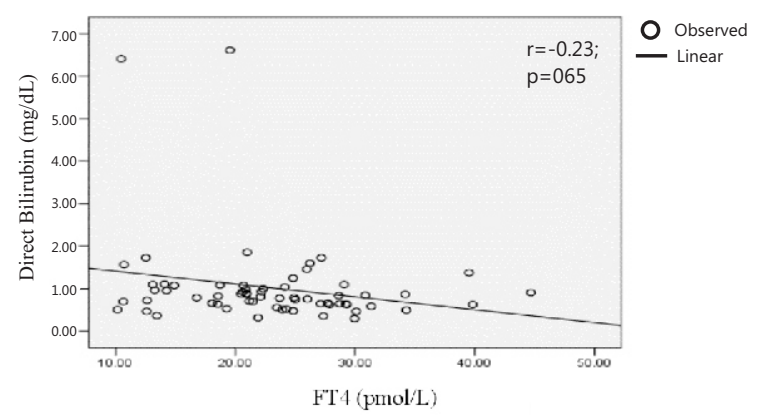

The scatter plot of correlation between FT4 and total bilirubin

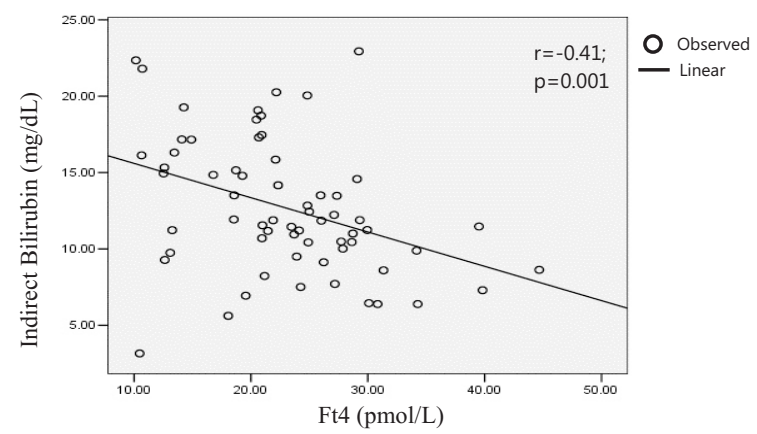

The scatter plot of correlation between FT4 and indirect bilirubin

Figure 2. The correlation between TSH, FT4, and serum bilirubin in all subject (the Spearman rank test)

There was a moderate negative correlation between TSH and serum total bilirubin levels in this study, indicating that a higher TSH level led to a lower total bilirubin level with $p=0.001(p<0.01)$.

This was in line with a study by Praveena, which showed a negative correlation between bilirubin, TSH, and T4 levels, but not statistically significant with T3 and total bilirubin $(r=0.026$ and $p=0.882)$, T4 with total bilirubin $(r=0.239$ and $p=0.167)$ and TSH with total bilirubin $(r=-0.069$ and $p=0.694) .{ }^{11}$

A study by Kayiran and Gurakan, which analyzed the relationship of TSH and thyroxine with third- day serum bilirubin levels detected through neonatal screening showed a significantly weak correlation from Pearson correlation analysis $(r=-0.19)$ between TSH and total bilirubin. There was no significant correlation between $\mathrm{T} 4$ and total bilirubin ( $r=-0.02)$, and between TSH and T4 $(r=-0.04){ }^{6}$ This study found a negative correlation between thyroid hormone and total bilirubin, a decrease in the level of thyroid hormone may cause prolonged indirect hyperbilirubinemia; this correlates with the delayed maturation activity of the UDPG-T enzyme. Decreased thyroid hormone 
in cases of indirect hyperbilirubinemia is caused by changes in thyroid hormone metabolism. This effect might involve inhibition of thyroid hormone uptake by target cells. A significant decrease in hepatic UDPG-T levels can be caused by the absence of thyroid hormone, or decreased UDPG-T activity. Delay in the uptake of bilirubin may also be a response or an indication of the absence of thyroid hormone, which occurs due to changes in maturation of ligandin or $Y$ protein as the basic protein responsible for substrate uptake by cellular metabolism. Ligandin binds to bilirubin and inorganic anions including drugs whose levels are low at birth. ${ }^{11}$

The thyroid-stimulating hormone in this study had a significant effect on the level of weak correlation with direct bilirubin levels, whereas FT4 and direct bilirubin had no significant correlation, and a negative correlation with moderate strength was obtained between TSH and FT4 with indirect bilirubin. This study showed an increase in indirect bilirubin (hyperbilirubinemia) and a tendency of normal direct bilirubin levels. Transient indirect bilirubin levels are found in neonates in the first week after birth. This is caused by a combination of increased erythrocyte production, conjugation of immature liver bilirubin (decreased hepatic clearance), and delayed intestinal transit. ${ }^{12}$

Physiological jaundice occurs in most neonates, which is considered a useful transition phenomenon, due to the anti-oxidant properties of indirect bilirubin. ${ }^{13}$ Jaundice is considered pathological if indirect bilirubin levels rise too rapidly, for example in jaundice after the first day of birth, or an increase in indirect bilirubin that exceeds $3.4 \mu \mathrm{mol} / \mathrm{L} / \mathrm{hour}$, and continues to increase for more than two weeks (prolonged jaundice). Pathologic unconjugated hyperbilirubinemia occurs largely due to excessive mechanisms that cause physiological jaundice such as increased bilirubin production and decreased hepatic clearance. $^{11}$

This study showed a negative correlation between TSH with total bilirubin levels. This finding was not in accordance with some references, which reported increased hyperbilirubinemia in the condition of congenital hypothyroidism. This was due to many hyperthyroid subjects in our study, of, which maternal TSH antibodies in neonates remain present. Animal studies showed that T3 is also involved in the mechanism of bilirubin, and its increased levels are thought to cause the accumulation of bilirubin precursors. Hyperthyroidism may cause an increase in cardiac output and heart failure, which may also contribute to abnormal liver function. However, this study merely used the cross-sectional study design; thus, a causal relationship between TSH, FT4, total bilirubin, direct and indirect bilirubin as well as other variables in subjects with neonatal jaundice were unable to be further analyzed.

\section{CONCLUSIONS AND SUGGESTIONS}

This study revealed that TSH and FT4 in neonatal jaundice were moderately correlated with total and indirect bilirubin. Thyroid-stimulating hormone had a weak correlation with direct bilirubin, while FT4 was not correlated with direct bilirubin. Further research should be performed to determine the correlation between TSH, FT4, and bilirubin in neonatal jaundice patients using a different research design, healthy controls, and multicenter.

Therefore, thyroid function screening is recommended to be performed in neonates with prolonged jaundice and a history of maternal thyroid during pregnancy, considering the importance of thyroid function in the function and formation of organs.

\section{ACKNOWLEDGMENTS}

Researchers would like to acknowledge PT Dexa Arfindo Pratama for the support of the FT4 and TSH kits used in this study.

\section{REFERENCES}

1. Kementrian Kesehatan Republik Indonesia. Peraturan menteri kesehatan no 78 tentang skrining hipotiroid kongenital. Jakarta, Kementrian kesehatan RI, 2014; 12.

2. Pankaj Agrawal, Rajeev Philip, Sanjay Saran, Manish Gutch, Mohd Sayed Razi, et al. Congenital hypothyroidism. Indian Journal of Endocrinology and Metabolism, 2015; 19(2): 221-227.

3. Kementerian Kesehatan Republik Indonesia. Modul pelatihan: Skrining Hipotiorid Kongenital (SHK) bagi petugas kesehatan. Jakarta, Kementerian Kesehatan RI, 2014; 3.

4. Annang GM, Galih H. Epidemiologi, pencegahan primer dan sekunder pada hipotiroid kongenital. Bagian Ilmu Kesehatan Anak FK UNS/RSUD Dr. Moewardi, Surakarta, 2016; 1-2.

5. Rastogi MV, La Franchi SH. Congenital hypothyroidism. Orphanet J Rare Dis. 2010; 5:17.

6. Kayran SM, Gurakan B. Correlation of third day TSH and thyroxine values with bilirubin levels detected by neonatal screening system. Medical Journal of Bakirkoy, 2010; 6(3): 117-120. 
7. Deetman PE, Bakker SJL, Kwakernaak AJ, Navis G, Dullaart RPF. On behalf of the PREVEND Study Group. The relationship of the anti-oxidant bilirubin with free thyroxine is modified by insulin resistance in euthyroid subjects. PLos One 2014; 9(3): e90886.

8. Chatur Nurin, Castro Marina, Young Tai Kin Fan. Macular rash, thrombocytopenia, and hyperbilirubinemia in a preterm infant. Hindawi Case Reports in Pediatrics 2019; 2019: Article ID 4076740.

9. Biondi B, Cooper D. The clinical significance of subclinical thyroid dysfunction. Endocrine Reviews, 2008; 2008: 761310016-3769.

10. Yardena Tenenbaum-Rakover. Approach to subclinical hypothyroidism in children, current topics in hypothyroidism with focus on development. Eliska Potlukova, IntechOpen, 2013; 2013: section 3.

11. Praveena Vithpala, Reddy Mettu, Jaju Jyotsna, Rishabyadati, Sudheer. Thyroid hormone levels in neonatal hyperbilirubinemia. Journal of Evolution of Medical and Dental Sciences, 2018; 7(28): 3224-3228.

12. Rigato I, Pascolo L, Fernetti C, Ostrow JD, Tiribelli C. The human multidrug-resistance-associated protein MRP1 mediates ATP-dependent transport of unconjugated bilirubin. Biochem. J.P, 2004; 383: 335-341.

13. Sedlak TW, Snyder SH. Bilirubin benefits: Cellular protection by a biliverdin reductase antioxidant cycle. Pediatrics, 2004; 113: 1776-1782. 